University of Warwick institutional repository: http://go.warwick.ac.uk/wrap This paper is made available online in accordance with publisher policies. Please scroll down to view the document itself. Please refer to the repository record for this item and our policy information available from the repository home page for further information.

To see the final version of this paper please visit the publisher's website. Access to the published version may require a subscription.

Author(s): Tom Wellings, Mark A. Williams and Matthew Pitts

Article Title: Customer perception of switch-feel in luxury sports utility vehicles

Year of publication: 2008

Link to published version: http://dx.doi.org/

10.1016/j.foodqual.2008.03.004

Publisher statement: None 


\title{
Customer perception of switch-feel in luxury Sports Utility Vehicles
}

NOTICE: this is the author's version of a work that was accepted for publication in Food Quality and Preference. Changes resulting from the publishing process, such as peer review, editing, corrections, structural formatting, and other quality control mechanisms may not be reflected in this document. Changes may have been made to this work since it was submitted for publication. A definitive version was subsequently published in Food Quality and Preference, [Vol 19 Iss 8 (Dec 2008), 737-746] DOI:10.1016/j.foodqual.20008.03.004

\section{Authors}

Tom Wellings, Mark A.Williams, Matthew Pitts

\section{Affiliations}

WMG, The University of Warwick, Coventry, CV4 7AL, UK

\begin{abstract}
Successful new product introduction requires that product characteristics relate to the customer on functional, emotional, aesthetic and cultural levels. As part of research into automotive Human Machine Interfaces (HMI), this paper describes holistic customer research carried out to investigate how the haptics of switches in luxury Sports Utility Vehicles (SUVs) are perceived by customers. The application of these techniques, including an initial proposal for objective specifications, is addressed within the broader New Product Introduction context, and benefits described.

101 customers of SUVs assessed the feel of automotive push switches, completing the tasks both in, and out of vehicles to investigate the effect of context. Using the semantic differential technique, hedonic testing, and content analysis of customers' verbatim comments, a holistic picture has been built up of what influences the haptic experience. It was found that customers were able to partially discriminate differences in switch-feel, alongside considerations of visual appearance, image, and usability. Three factors named 'Affective', 'Robustness and Precision', and 'Silkiness' explained $61 \%$ of the variance in a principle components analysis. Correlations of the factors with acceptance scores were $0.505,0.371$, and 0.168 respectively.
\end{abstract}

\section{Keywords}

Automotive HMI, haptics, User-centred design

\section{Introduction}

\subsection{The changing nature of customer research in New Product Introduction}

The question of which methods, processes and factors are necessary for successful New Product Introduction (NPI) is one of perennial importance. Since the 1980's numerous benchmarking studies have been conducted to identify best practice and common factors evident in successful companies. It has consistently been found that the extent to which customer research is used and integrated within an NPI process, together with a process that is firmly implemented, are two of the strongest discriminators between best and worst performing businesses (Cooper, Edgett, and Kleinschmidt, 2004, Cooper and Kleinschmidt, 1991, Griffin, 1997, Kahn, Barczak and Moss, 2006). 
In saturated markets however, traditional market research techniques are no longer effective in generating new sales. Segmenting markets and producing ever less differentiated products has lead to increased innovation pressure, shorter product life cycles, and increased marketing costs. In response to these challenges, it is necessary for businesses to develop new strategies which improve customer 'value' by understanding people's priorities rather than their wishes (Carbonaro and Votava, 2005). Where previously, giving form to objects, and ensuring functional adequacy were the first concern; this has now expanded to encompass the emotional, behavioural, and cultural contexts in which product use takes place (Boztepe, 2007, Desmet and Hekkert, 2007). This holistic approach to customer research frequently draws together information from multiple sources such as desk research, observation, and qualitative and quantitative evidence, in order to present recommendations in the context of the business decision making process (Smith and Fletcher, 2004).

The challenge for manufacturing companies is to incorporate these research methods into their NPI processes and to utilise the findings effectively in engineering departments as well as within marketing and design. Lofthouse, Bhamra and Burrow (2005) describe a case study where an industrial fibre manufacturer has utilised consumer research in a technical team unused to direct customer input. Using the Kano method and qualitative participatory tools the manufacturer was able to understand how the end customer perceives their fibre, develop new relationships within the supply chain, and enhance multidisciplinary team working and decision making. Based on a method originally developed for the automotive industry (Burns and Evans, 2002), the benefits of holistic research are illustrated, whilst also demonstrating how techniques developed for one industry can be successfully adapted and applied to another.

\subsection{Specifications and communication}

No matter how well developed understanding is of the customer, their notions of value and their context of product use, if this knowledge can not be communicated between business functions, and applied effectively throughout the NPI process, then the delivered product will not achieve the business' strategic aims (Veryzer and Borja de Mozota, 2005). It is noted by van Kleef, van Trijp, and Luning (2005) that consumer research when applied to product development ... should provide: (1) an understanding of what drives consumers' decision processes, and (2) concrete output for subsequent product development.

It has been argued that high levels of cross-functional integration enhances the diffusion of market and customer knowledge amongst all members of the project team (Song and Parry, 1997), however this alone is not sufficient to ensure the message gets communicated. An equally important problem lies in the difficulty of translating subjective customer opinion into a usable metric or specification. In an automotive case study, Wellings, Williams, and Tennant (2005) found examples of disconnects in the NPI process relating to communication of product strategy, and the presence of quantified targets. Where targets did exist, they tended to be at a component level, and often only related vaguely to the customer's holistic perception of quality.

To try and address these issues numerous methods have been developed. The most well established approaches being Quality Function Deployment (QFD), Kansei Engineering, and the Kano Model, although there are others which can be grouped under the broad heading of affective design, or affective engineering. These tend to place a greater emphasis on the role of emotion, product semiotics, aesthetics, and the experience of human-product interaction.. (e.g. Khalid and Helander, 2004, Liu, 2003)

QFD as a method has its foundations in Japanese total quality management processes of the 1970's. It correlates customer wants or needs - presented in the customers' words - with design attributes and production related parameters, i.e. the proposed solutions to the identified customer needs. These are presented in matrices known as Houses of Quality, which also note the degree of importance to the customer of their particular 'wants'. QFD is multidisciplinary in nature, and teams contain members from a variety of different business departments. One of its advantages is that the visual format of presenting the data makes it easy to understand for both technical and non-technical team members. (Griffin and Hauser, 1993, Marsot, 2005)

Kansei Engineering aims to understand the relationship between the formal and experiential properties of a product. It is not a single approach, but rather a suite of methodologies that bear some similarities with the discipline of sensory science. Simplistically, there are two main concepts. In one, individual properties of a product are varied in a controlled manner, and rated on affective scales by the user. 
Statistical methods such as cluster analysis are then used to link the two. The second approach starts with a qualitative investigation of in-context product use in order to identify the experiential needs of the user. Different product concepts are then developed with the aim of satisfying these needs. In some cases the concepts or samples are subsequently validated through cluster analysis of data from semantic rating scales. (Jordan, 2000, Schütte, Eklund, Axelsson, and Nagamachi, 2004)

The Kano model has again come out of work on quality management carried out in Japan. It is a method for sorting the features of a product into various quality categories based on a questionnaire filled out by customers. At its core is the concept that the relationship between fulfilment of a need and customer satisfaction is not always linear. This leads to product features being categorised as one of three types: must-have attributes (if not present, dissatisfaction will result, but they cannot improve satisfaction), linear attributes (the level of delivery is proportional to the level of satisfaction), and delighter attributes (these do not dissatisfy when absent, but can delight when present). (Centre for Quality of Management, 2003, Riviere, Monrozier, Rogeaux, Pages, and Saporta, 2006)

Although some of these methods appear to offer a 'scientific' approach to incorporating the 'voice of the customer' in product development, it is important to recognise that people do not always conform to rigid rules, and an understanding of human variability is necessary to avoid erroneous application of findings. For example, faced with the commercial constraints of time and cost, it is tempting for companies to fall back on product assessments using internal employees as participants. Literature shows however that users' perception of products differs significantly from experts or company employees, and should be treated with caution (Hsu, Chuang, and Chang, 2000, Karlsson, Aronsson, and Svensson, 2003).

\subsection{Haptics and the Human Machine Interface}

Interaction, by definition involves some form of sensory experience. The most frequently researched modalities are visual and auditory (e.g. Creusen and Schoormans, 2005, Lyon, 2003), however haptics presents an under researched opportunity for increasing customer satisfaction. Forbes magazine listed haptics as one of 'ten things that will change the way we live' (Ely, 2006), and evidence of its impact surround us. Ranging from navigation aids for the visually impaired to virtual medical training simulators, to force feedback computer gaming interfaces and vibrotactile mobile phones (Immersion, 2007).

In the case of cars, at the vehicle level haptic quality has been identified by manufacturers as playing an important role in the relationship between user and vehicle, and is integral to the formation of value judgements. Consider for example, how opening a heavy, solid feeling car door communicates the impression of quality (Macdonald, 2001). At a user interaction level exploiting the haptics of Human Machine Interfaces (HMI) in future cars will be vital as technological complexity rapidly increases, and the communication between human and machine takes on ever greater importance (Benson, MacRury, and Marsh, 2007). Interaction with user controls - including buttons and switches - will have to reflect the value expectations of the customer as well as satisfying functional and sensory criteria (Schütte and Eklund, 2005). This paper seeks to demonstrate how sensory science and design research methods can successfully be applied in the development of non-food products such as automotive HMI.

\subsection{Research questions}

The difficulty with researching car interiors lies in the complexity of factors that influence customer opinion, as well as the way products are developed. Individual teams are responsible for specific components or systems, and therefore require detailed customer research that may not be provided by conventional vehicle wide market research. By considering the context of usage this work focuses on building up a holistic picture of automotive switch-feel in European market luxury SUVs from the perspective of the customer. It seeks to understand which aspects of switches are the drivers of satisfaction. For example: shape, force of actuation, materials, or perhaps extrinsic factors like brand expectations. The work is structured to provide information that is usable in specific current and future vehicle development programmes, and the research questions it answers can be stated as follows:

- $\quad$ Can luxury SUV customers perceive differences in switch-feel?

- $\quad$ As a group, do luxury SUV customers show common hedonic judgements for switch-feel? 
- What are the switch characteristics that influence perception of switch-feel?

To answer these questions, outputs include quantitative hedonic data on push switches, qualitative insights into what customers like or dislike about centre console switches, and design guideline hypotheses for maximising customer satisfaction.

\section{$2 \quad$ Materials and Methods}

\subsection{Participant Sampling}

The participants taking part in the sensory evaluation were 101 owners, or principle drivers of luxury SUVs. The event took place in the UK, and the participants were UK residents; although the gender split, age profile, and approximate numbers of each SUV owned were defined through proprietary market research data to be representative of the European SUV market. It was decided to base the sample demographics on European, rather than the narrower UK market data because vehicles destined for countries within the European Union (EU) are governed by common legislation resulting in little endmarket variation (Vehicle Certification Agency, 2001). It is however acknowledged that customers in different countries will most probably have different wishes and product expectations. Summary details are shown in Table 1.

Table 1: Summary of participant sample for the customer event

\begin{tabular}{llrr}
\hline Description & Category & Count & $\begin{array}{r}\text { \% of } \\
\text { Total }\end{array}$ \\
\hline \multirow{3}{*}{ Sex } & male & & \\
& female & 73 & $72 \%$ \\
& Total & 28 & $28 \%$ \\
Age & & $\mathbf{1 0 1}$ & $\mathbf{1 0 0 \%}$ \\
& $21-30$ & & \\
& $31-40$ & 5 & $5 \%$ \\
& $41-50$ & 29 & $29 \%$ \\
Vehicle Owned & $31-60$ & 27 & $30 \%$ \\
& BMW X5 & 10 & $10 \%$ \\
& Volvo XC90 & 19 & \\
& Range Rover Sport & 15 & $19 \%$ \\
& Mercedes M-Class & 12 & $12 \%$ \\
& Range Rover & 11 & $11 \%$ \\
& Others & 16 & $16 \%$ \\
\hline
\end{tabular}

a $\%$ rounded to nearest whole number

\subsection{Automotive switch samples}

Push switches from the infotainment unit in the centre console area of European specification luxury SUVs were chosen as samples for the assessment. This is an area of high importance for driver/passenger interaction with the vehicle, and it has also been shown that focussing on a specific component rather than the interior as a whole leads to more usable data that relates better to specific aspects of the design (Jindo and Hirasago, 1997).

The vehicles were specified to have comparable interior trim levels dependent on criteria such as having satellite navigation and electrically adjusted leather seats, and were labelled 'A' to 'E'. A duplicate set of unbranded standalone switch-packs, identical to those switches assessed within the vehicles were also assessed. These had different alphabetic labels from the vehicles in order to reduce the association with the brand of the vehicle they came out of. Fig 1 shows the vehicles and the separate switch-packs. 

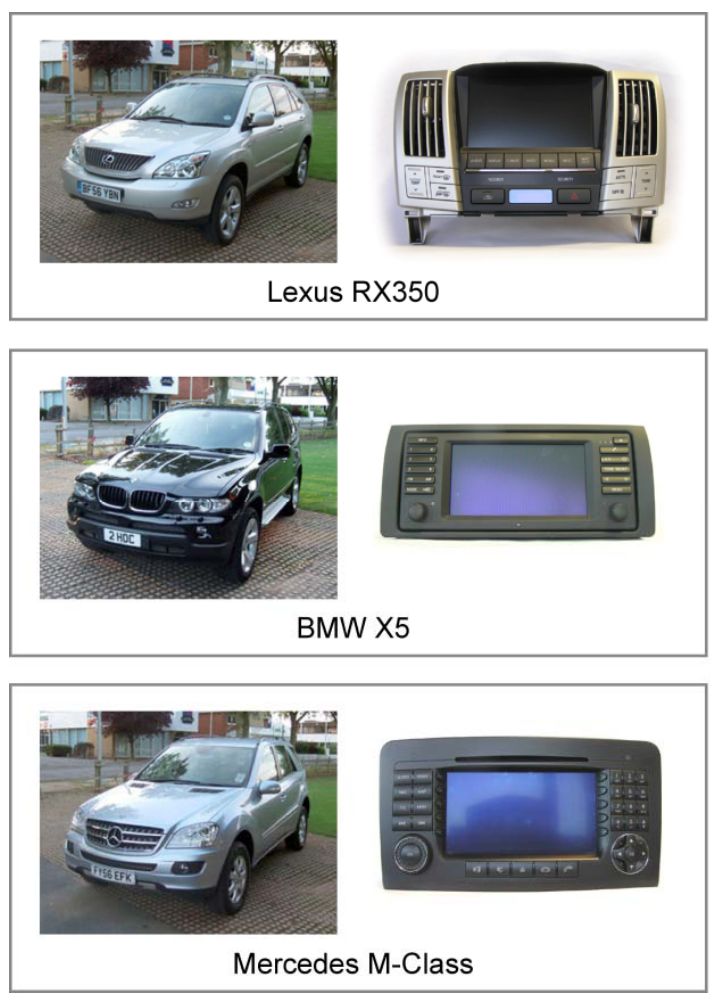
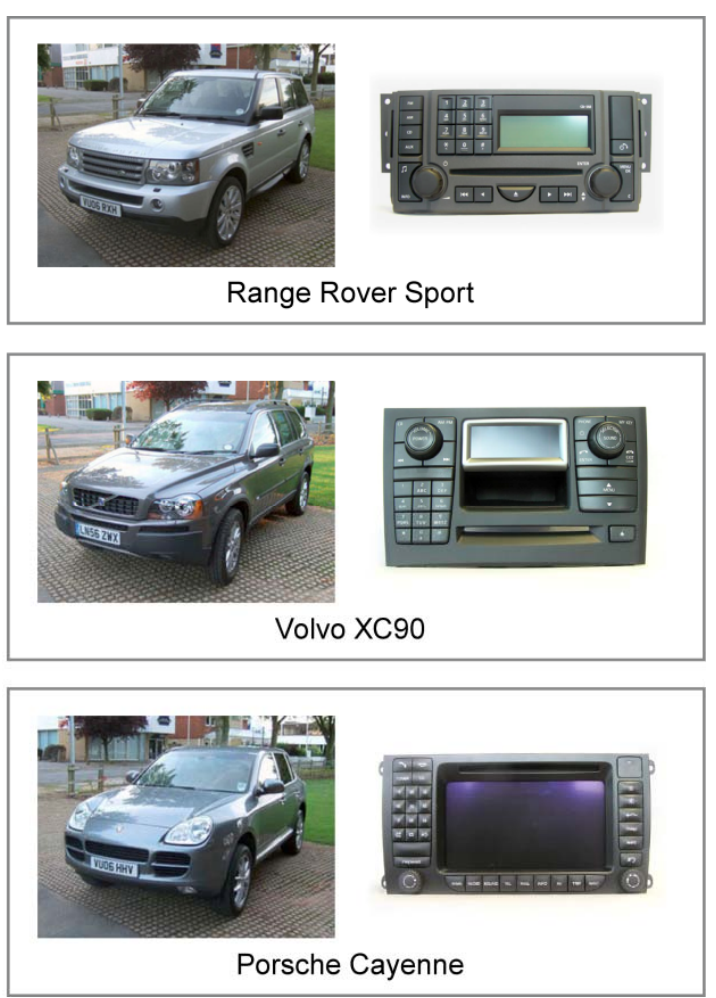

Fig 1: Vehicles and stand-alone switch-packs used in the switch research event

\subsection{Experimental design and procedure}

Assessment of the switches was conducted through a counterbalanced design under two sets of conditions: in-context, whilst seated in the vehicle, and out of context conducted on a bench top. Within either situation, participants assessed the switches in a random order. For the in-context assessment the vehicles were sited in a large room in a location unconnected with any manufacturer. The brands were visible, because in the majority of cases, the participants were already familiar with at least one of the models present, and capturing the 'real-life' perception of switch-feel was important. For the out of context assessment, the switch-packs were unbranded and in a separate screened off area. The potential benefit of the counterbalanced design is to even out any bias from in-context assessments, whilst maintaining a component of realism in the product usage situation. Analysis of the differences in acceptance ratings under the two conditions will determine whether these data sets should be combined for more detailed statistical analysis

The assessment tasks carried out under each condition were identical, and consisted firstly of a semantic differential test, followed by hedonic testing. Several sessions were run over the course of two days, with groups of up to ten participants in each.

Participants were first asked to spend a few minutes trying out the relevant push-switches in all the vehicles, or on-bench switch-packs. This was to familiarise themselves with the range of different feel characteristics present, and help define the extremes of the switch-feel domain. It was emphasised that the focus should be on the 'feel' of the switches only, and not their impression of the whole vehicle interior. Following this acclimatisation period, vehicles or switch-packs were assessed one by one, and the data collected using self-administered questionnaires in which annotated images showed the switches to be assessed. Participants were asked not to discuss their opinions with each other, especially during the onbench stage where there was a risk of identifying the unbranded switch-packs to others.

The semantic differential technique as developed by Osgood, Suci, and Tannenbaum (1957) asks participants to rate a concept (or in this case, a subjective impression) on a series of seven point Likert scales anchored at each end with bipolar adjectives. The scale categories were labelled 'extremely' 'quite' - 'slightly' - 'neutral' - 'slightly' - 'quite' - 'extremely'. The 11 bi-polar word pairs used in the 
assessment were derived from a larger list of 261 adjectives, which in turn had been collected through analysis of qualitative data from a previous automotive switch study. In addition, literature where switches, human machine interfaces, and interaction were the central topics were also analysed (Schütte et al., 2004). To reduce the extended adjective list down to 11 bi-polar pairs, a frequency analysis was conducted (Hsu et al., 2000), and then semantically similar words removed. As the overall objective of the work was to investigate perception of switch haptics, there are fewer adjectives specifically pertaining to the senses of vision, sound, taste or smell. It was intended however that the word pairs represented participants' personal understanding of switch-feel, and so the chosen word pairs were pre-tested in a pilot study with 18 subjects and further refined where a lack of understanding was evident. The final list of 11 word pairs are shown in Table 2 . The intention was to take approximately 25 minutes to carry out the semantic differential assessment; hence the list of adjectives pairs is small.

Table 2: Bipolar adjective pairs used in semantic differential rating tasks

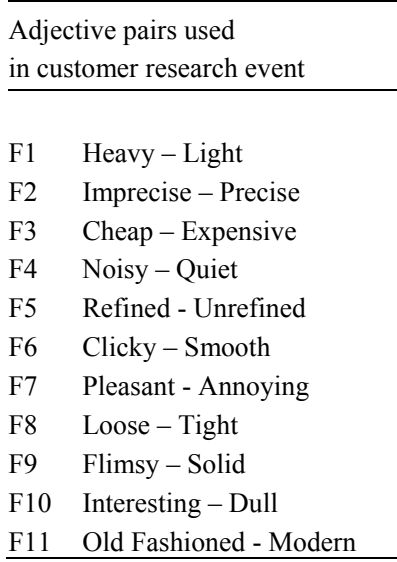

Three additional pieces of data relating to the owners' hedonic perception of switch-feel were also collected. Firstly, participants had to choose one set of switches they most preferred the feel of, and one set they least preferred the feel of, giving qualitative reasons for each choice. Liking for switch-feel was then rated using ten point scales, where $1=$ dislike switch-feel, and $10=$ like switch-feel.

The authors acknowledge that by performing the semantic differential test before the hedonic testing, there may be some carry over of the semantic terms into the qualitative reasons given for preference. In this study however, it was decided the semantic differential assessments on all six vehicles needed to be carried out with minimum delay between them in order to maximise the impressions held in sensory memory. This precluded a reversal of the tasks.

\subsection{Data analysis strategy}

Quantitative data collected from within-participants studies are often analysed using parametric statistical methods such as repeated measures ANOVA. In order that the results are reliable however, these methods rely on certain assumptions being satisfied, notably those of distribution normality and the data being interval or ratio scaled. There is much discussion over whether rating data can statistically be considered as scale data (Kinnear and Gray, 2006; Sheldon, Fillyaw, and Thompson, 1996; Warnock, Shumaker, and Delwiche, 2006), and so to avoid this issue, nonparametric analysis techniques have been used. The Wilcoxon Signed Ranks test investigates differences in acceptance related to context of assessment, and the rank-based Friedman test (Daniel, 1990) has been used to investigate participants' ability to discriminate differences in switch-feel, as well as differences in the semantic attributes for the six samples. A Chi-square goodness of fit test has been used to check for significant differences in the categorical preference data.

Exploratory principal component analysis (PCA) with Varimax rotation has been used to develop a model describing the major underlying factors of switch-feel perception. The analysed matrix had the bipolar scales as the variables, and participant ratings combined across the six switch samples as the observations. 
The qualitative hedonic data has been analysed using content analysis (Krippendorff, 2004, Silverman, 2006). This technique enables replicable and valid inferences to be drawn, and provides a quantitative indication of importance of the varying concepts integral to switch-feel preference.

\section{$3 \quad$ Results}

\subsection{Hedonic assessments of switch-feel}

\subsection{Acceptance rating}

Prior to more detailed statistical analyses, a preliminary visual exploration of the ratings data has been carried out to examine distribution and normality. As is common with acceptance ratings, all six switchpacks received a broad range of responses (ranges of 9 or 10). This was true whether assessments took place in or out of context. It was also evident that many of the samples had non-normal distributions. When assessed in-car, the Lexus RX350, BMW X5, and Range Rover Sport exhibited bimodality, and when assessed on-bench the Range Rover Sport was again somewhat bimodal.

Median acceptance scores are reported in Table 3, alongside results of a Wilcoxon Signed Ranks test. This investigates whether there were significant differences in consumer acceptance for switches assessed in, and out of context. It has been shown that the Mercedes M-Class and Range Rover Sport differed significantly $(p<0.05)$, the Volvo was close to significance at the same level $(p=0.06)$, but the other three switch samples were not. Based on these findings, it was decided that the two data sets should not be combined, and for further quantitative analyses, only data from the in-car assessments has been used.

The in-context median scores indicate that the Mercedes has the most liked switch-feel, with the Porsche and BMW being jointly liked the least

Table 3: Median acceptance scores, and Wilcoxon signed ranks test results showing significant differences between in and out of context assessments

\begin{tabular}{|c|c|c|c|c|c|c|}
\hline & $\begin{array}{c}\text { Merc } \\
\text { M-Class }\end{array}$ & $\begin{array}{l}\text { Lexus } \\
\text { RX350 }\end{array}$ & $\begin{array}{l}\text { Volvo } \\
\text { XC90 }\end{array}$ & $\begin{array}{l}\text { Range Rover } \\
\text { Sport }^{\text {a }}\end{array}$ & $\begin{array}{l}\text { Porsche } \\
\text { Cayenne }\end{array}$ & $\begin{array}{c}\text { BMW } \\
\text { X5 }\end{array}$ \\
\hline $\begin{array}{l}\text { Median liking rating } \\
\text { (assessed in-car) }\end{array}$ & 7 & 6 & 6 & 6 & 5 & 5 \\
\hline $\begin{array}{l}\text { Median liking rating } \\
\text { (assessed on-bench) }\end{array}$ & 6 & 7 & 6 & 4.5 & 5 & 4 \\
\hline Asymp. Sig. (2-tailed) & .02 & .78 & .06 & .00 & .14 & .50 \\
\hline
\end{tabular}

The rank based 'Friedman Test' has been employed to examine the participants' ability to discriminate differences in switch-feel. This was followed by a 'least significant difference' post hoc analysis to establish where significant differences occurred (Daniel, 1990). The Friedman test results in Table 4 show that at least one of the median ratings is significantly different from the others $\left(\chi^{2}=19.4, p<0.01\right)$. The post hoc analysis (familywise error $\alpha=0.05$, per-comparison $\alpha=0.0017$, least significant difference $=$ 77.9) shows that the only significant difference occurs between the Mercedes M-Class and the BMW X5. These vehicles received the highest and lowest hedonic ratings in terms of switch-feel, and they are also the most and least preferred respectively, as reported in the following 'preference test' section.

Table 4: Results of Friedman Test and post hoc analysis showing significant differences in hedonic scores for in-car assessments

\begin{tabular}{llll}
\hline Friedman test & \multicolumn{3}{c}{ Post hoc analysis } \\
\hline Vehicle's switches & In-car & Comparison pairs & Absolute difference in \\
& mean rank $^{\mathrm{a}}$ & of switches & sum of ranks (in-car) \\
\hline
\end{tabular}




\begin{tabular}{|c|c|c|c|c|}
\hline Lexus RX350 & 3.4 & Lexus - BMW & $=$ & 66 \\
\hline BMW X5 & 4.0 & Lexus - Merc & $=$ & 43.5 \\
\hline Merc M-Class & 2.9 & Lexus - RR & $=$ & 17.5 \\
\hline RR Sport & 3.6 & Lexus - Volvo & $=$ & 7.5 \\
\hline Volvo XC90 & 3.5 & Lexus Porsche & $=$ & 27.5 \\
\hline \multirow[t]{2}{*}{ Porsche Cayenne } & 3.7 & BMW - Merc & $=$ & $109.5^{\mathrm{b}}$ \\
\hline & & BMW - RR & $=$ & 48.5 \\
\hline \multicolumn{2}{|c|}{ Friedman Test Statistics } & BMW - Volvo & $=$ & 58.5 \\
\hline $\mathrm{n}$ & $100^{\mathrm{c}}$ & BMW - Porsche & $=$ & 38.5 \\
\hline Chi-Square & 19.4 & Merc - RR & $=$ & 61 \\
\hline Deg. of freedom & 5 & Merc - Volvo & $=$ & 51 \\
\hline \multirow[t]{4}{*}{ Significance $(p)$} & .002 & Merc - Porsche & $=$ & 71 \\
\hline & & RR - Volvo & $=$ & 10 \\
\hline & & RR - Porsche & $=$ & 10 \\
\hline & & Volvo - Porsche & $=$ & 20 \\
\hline
\end{tabular}

\footnotetext{
${ }^{\mathrm{a}}$ Ties are assigned a mean rank position

${ }^{\mathrm{b}}$ Significant differences with familywise error $\alpha=0.05$ (absolute sum of ranks $>77.9$ )

${ }^{\mathrm{c}}$ One missing participant response
}

\section{Preference test}

Frequency counts for the most and least preferred switch-feel (in-car assessment data) are presented in Fig 2. It can be seen that in absolute terms, the Lexus has the most preferred switches $(+28)$, and the Range Rover Sport the least preferred (-26). Chi-square tests reveal the presence of significant differences in frequency counts within the six vehicles' switches for both most preferred $\left(\chi^{2}=26.65, p<0.01\right)$, and least preferred $\left(\chi^{2}=15.12, p<0.01\right)$ data sets.

By combining positive and negative opinion, the net differences in counts shown in Fig 2 are more similar to an average measure of liking than the absolute counts. Mirroring the hedonic ratings results in Table 3, the net counts show the Mercedes as the most favoured (+21), and the BMW (-10) the least.

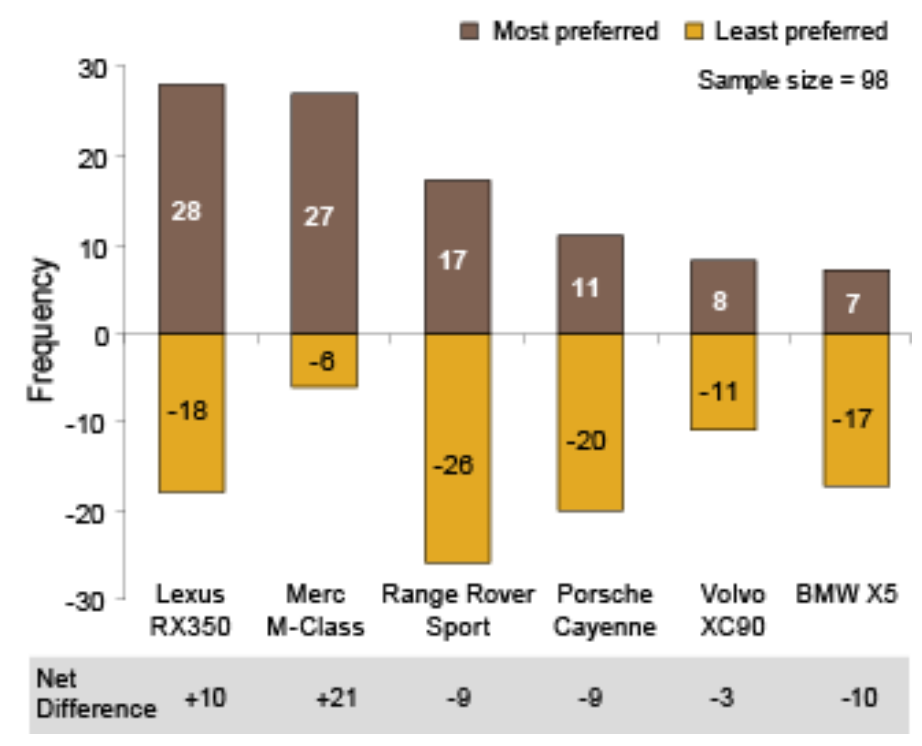


Fig 2: Absolute frequency counts of most and least preferred switch-feel (in-car assessment) together with net differences. N.B. three missing responses from participants

\subsection{Semantic Differential test}

Fig 3 shows the mean rating scores for the eleven variables plotted for the Mercedes M-Class and BMW X5 switches. For clarity, only these two profiles are shown because they have been rated as having the most and least preferred switch-feel respectively, and so represent the extremes of opinion for this product set. They were also the only two products that showed a significant difference in their hedonic ratings (see Table 3).

An initial visual examination of the semantic profiles for all six vehicles' switches reveals differences in the magnitudes of the rating scores, inferring that their perceived characteristics may also differ.

Friedman tests and post hoc multiple comparisons were again used to establish if these differences were statistically significant.

The results of the Friedman Tests show significant differences exist $(p<0.01)$ between the six samples for each of the eleven word pairs. Post hoc multiple comparisons (familywise $\alpha=0.05$, least significant difference $=78$ ) reveal that 50 out of the 165 total comparison pairs are significantly different in scores. The encircled data points in Fig 3 denote the differences for this pair of samples.

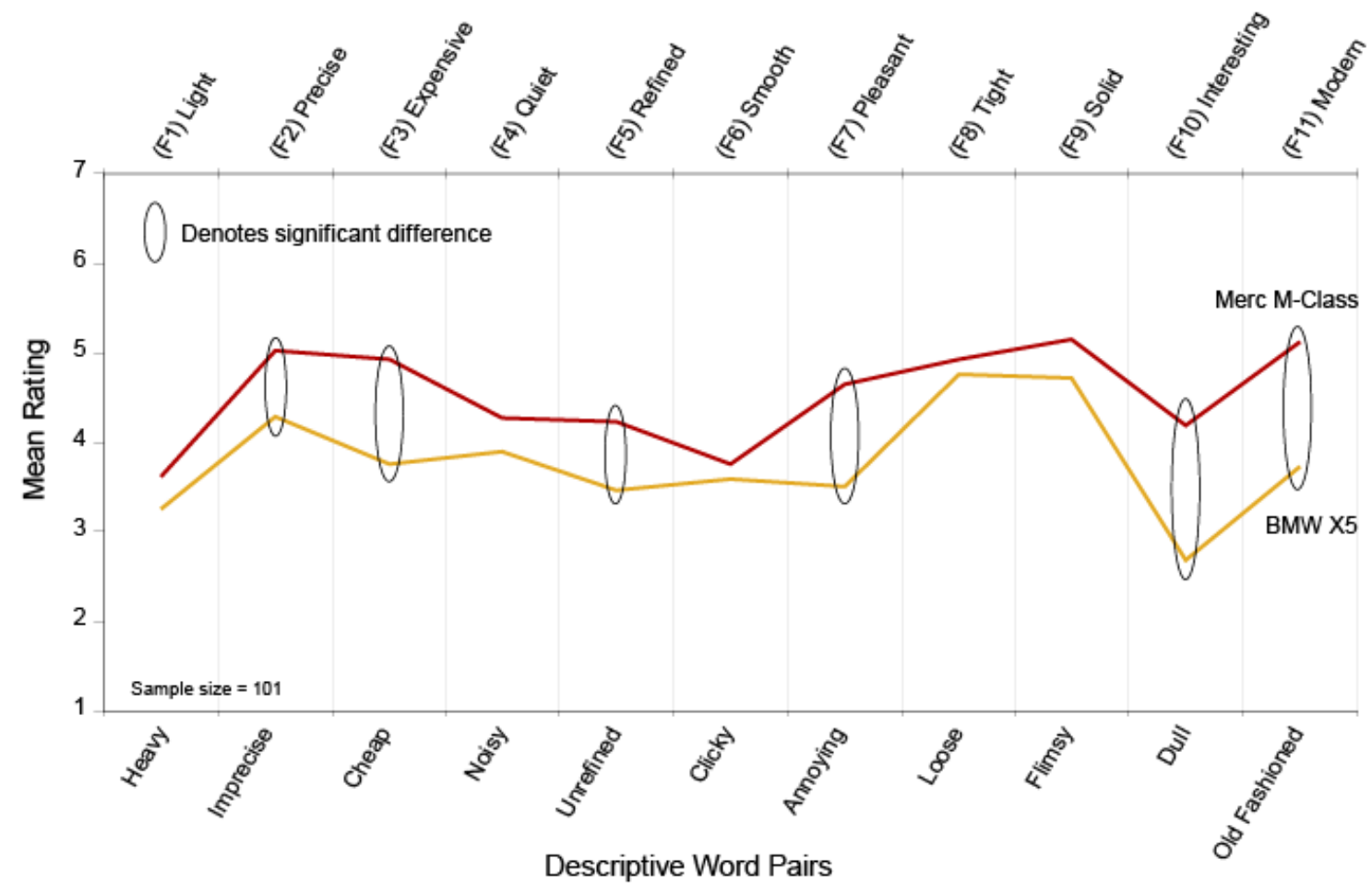

Fig 3: Profiles of mean semantic differential rating scores for push switches assessed in-car. Ellipses denote significant differences

\section{$5 \quad$ Principle Components Analysis}

An exploratory Principle Components Analysis (PCA) has been carried out on the combined in-car data for all six vehicles with the aim of reducing the number of variables from the original eleven, and identifying the common underlying factors.

Firstly, it was checked that the data was suitable for factor analysis. Sampling adequacy was high (KMO $=0.81$ ), and correlation between variables was evident with at least one correlation coefficient above 0.4 for each variable. (Bartlett's sphericity test: $\chi^{2}=1723$, significance $\mathrm{p}<.01$ ). Varimax orthogonal rotation was used to attain simple structure, and three factors extracted. For this sample size of 101 participants, 
significant factor loadings have been calculated as those greater than 0.512 (two times the standard error of correlation coefficient at $\alpha=0.01$, two tailed test). (Stevens, 2002)

Table 5 shows the PCA factor loadings. Overall, the three factor model accounts for $61 \%$ of the variance in the data. Factor 1 explains 33\% of the variance, and contains positive loadings for dull-interesting, annoying-pleasant, unrefined-refined, and old fashioned-modern. This has been named as the 'Affective' factor, due to the largely emotional connotations of the variables. Cheap-expensive loads mainly onto factor 1, but also onto factor 2. Factor 2 explains $16 \%$ of the variance, and comprises loadings for flimsysolid, loose-tight, and imprecise-precise. These variables relate to the perceived physical operation and construction of the switches, and it has been denoted 'Robustness and Precision'. Factor 3 is loaded by clicky-smooth, noisy-quiet, and heavy-light, and explains $12 \%$ of the variance. This has been named 'Silkiness'.

Table 5: PCA factor loadings and percentage variance explained by each factor for luxury SUV switch-feel, as evaluated in-car by vehicle owners.

\begin{tabular}{|c|c|c|c|}
\hline \multirow[b]{3}{*}{ Semantic pairs } & \multicolumn{3}{|c|}{ Factor Loadings ${ }^{a}$} \\
\hline & Factor $1(33 \%$ & Factor $2(16 \%)$ & Factor $3(12 \%)$ \\
\hline & Affective & Robustness \& Precision & Silkiness factor \\
\hline Dull-Interesting & .798 & & \\
\hline Annoying-Pleasant & .751 & & \\
\hline Unrefined-Refined & .743 & & \\
\hline Old Fashioned-Modern & .609 & & \\
\hline Cheap-Expensive & .592 & .458 & \\
\hline Flimsy-Solid & & .792 & \\
\hline Loose-Tight & & .766 & \\
\hline Imprecise-Precise & & .621 & \\
\hline Clicky-Smooth & & & .802 \\
\hline Noisy-Quiet & & & .766 \\
\hline Heavy-Light & & -.325 & .708 \\
\hline
\end{tabular}

${ }^{\mathrm{a}}$ Factor loadings less than .3 have been disregarded

To gain a greater understanding of which aspects of switch-feel are associated with liking, overall factor scores have been correlated with the hedonic ratings (Table 6). Significant correlations $(p<0.01)$ are observed with all three factors, ranging from 0.505 for the affective factor, through 0.371 for the robustness and precision factor, to a somewhat small value of 0.168 for the silkiness factor.

Table 6: Correlations between in-car hedonic scores and in-car PCA factor scores

\begin{tabular}{lllll}
\hline & $\begin{array}{l}\text { In-car hedonic } \\
\text { rating }\end{array}$ & factor score 1 & factor score 2 & factor score 3 \\
\hline In-car hedonic rating & 1 & $.505^{\mathrm{a}}$ & $.371^{\mathrm{a}}$ & $.168^{\mathrm{a}}$ \\
factor score 1 & 1 & .007 & -.005 \\
factor score 2 & & 1 & .001 \\
factor score 3 & & & 1 \\
\hline
\end{tabular}

${ }^{a}$ Correlation is significant at the 0.01 level (2-tailed).

\subsection{Content analysis of qualitative preference data}

The qualitative data comprises of the reasons given for why participants 'most' or 'least' preferred the feel of a switch. The decision was taken to combine data from the in-car and on-bench assessments after inspecting the most commonly cited reasons given in each treatment. When compared, the rank order of 
the top seven most common categories were the same which suggests that there is substantial similarity in reasons given for preference between both data sets.

The data has been divided up into discrete concepts to give 456 individual 'most preferred' comments, and 393 'least preferred' comments. Seventy four categories (35 positive, 39 negative) were defined in an exploratory process, to which the comments were then assigned. Two of the authors independently coded the comments and assigned them to categories. Comparing these two sets of coded data showed intercoder agreement of $89 \%$.

Fig 4 shows the top ten most common categories for positive comments. The most common positive comments are those in the 'general praise' category (17\% of the total positive comments). These are straightforward affective affirmations of the product, e.g. "nice feel" or "good to look at". The second most common category - 'size' - contains comments related to switch size e.g. "large switches". The third most common category has comments describing the 'precision' of the switch operation. In addition to switch size, there are three other categories in the top ten related to usability. These are 'ease of use' (e.g. "easy to operate"), 'layout and spacing' (e.g. "well laid-out"), and 'legibility' (e.g. "easy to read").

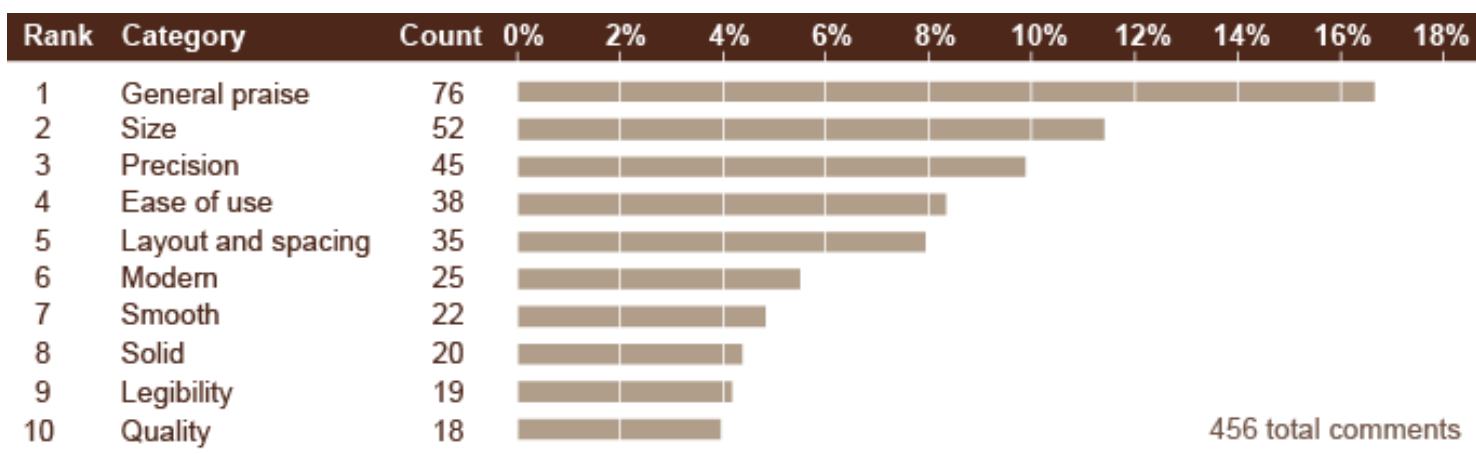

Fig 4: Top ten most common categories of positive comments relating to switch-feel (combined in-car and on-bench data)

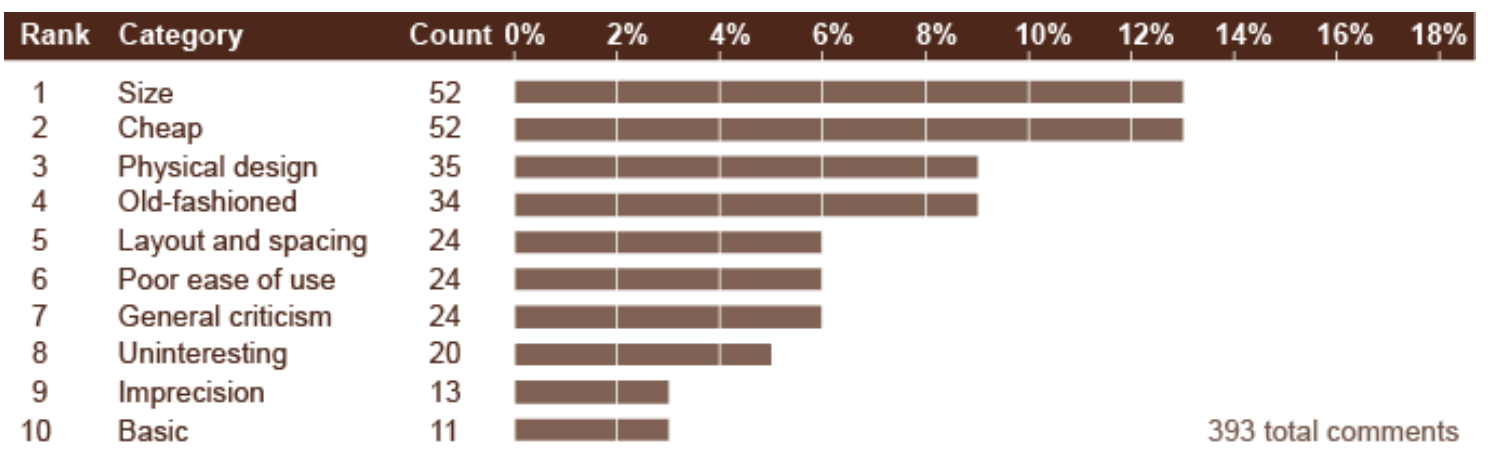

Fig 5: Top ten most common categories of negative comments relating to switch-feel feel (combined in-car and on-bench data)

The 'least preferred' data in Fig 5 shows 'size', along with 'cheapness' to be the most commonly given reasons for not liking the feel of a switch (13\% of the total negative comments each). Cheapness contains comments such as "feels quite cheap", and "looks cheap". The third most common category has comments describing physical design aspects of the switches. These are dominated by dissatisfaction with using top-hinged, and rocker switches, i.e. switches that are not simple linear push switches.

To gain more insight into what the participants mean by 'cheap', the context surrounding the use of the phrase was analysed in more depth. It has been found that the most commonly occurring comments cited 
alongside 'cheapness' related to usability issues; particularly size, spacing and layout. Comments related to the switches being 'old-fashioned', 'imprecise', 'and 'uninteresting' also featured.

\section{Size, layout and spacing of switches}

Switch size has been shown to be important to the participants in both the positive and negative data. Fig 6 shows how customer opinion varies between the different product examples. From the participant responses, and physical measurements of the switches, it appears that there may be a relationship between size of switch and hedonic judgements. Generally, larger switches are preferred more than small switches, with the size of the Volvo switches being liked the most.

\begin{tabular}{|c|c|c|c|c|}
\hline & dislike switch size & like switch size & $\begin{array}{l}\text { min switch dimensions } \\
(W \times H \text { in } m m)\end{array}$ & $\begin{array}{l}\text { min switch area } \\
\left(\mathrm{mm}^{2}\right)\end{array}$ \\
\hline Volvo & 5 & 20 & $18 \times 15$ & 270 \\
\hline Lexus & 10 & 17 & $20 \times 20$ & 400 \\
\hline RR Sport & 3 & 7 & $13 \times 14$ & 182 \\
\hline Mercedes & 6 & 5 & $12 \times 14$ & 168 \\
\hline BMW & 8 & & $15 \times 9$ & 135 \\
\hline Porsche & 20 & 2 & $11 \times 12$ & 132 \\
\hline
\end{tabular}

Fig 6: Distribution of comments relating to switch size (combined in-car and on-bench data) together with physical dimensions

The same rationale can be applied to the related issue of 'layout'. The results of this analysis are shown in Fig 7. Overall, the Lexus had the most liked layout, whereas the Porsche was perceived most negatively.

Potentially reflecting Kano model's view of product quality, it appears that reasons for liking or disliking the layout of switch-packs differ somewhat. Positive responses include factors such as being able to find the switches easily in the dark, overall number of switches, and how spread out they are. Reasons for disliking the layout however are predominantly related to how close together the switches are, as illustrated by the following participant's comments:

"Buttons close together - hard to get a precise action"- [female participant referring to the Porsche switches]

"Very close...people with big fingers will easily suffer here" - [male participant referring to the BMW switches] 


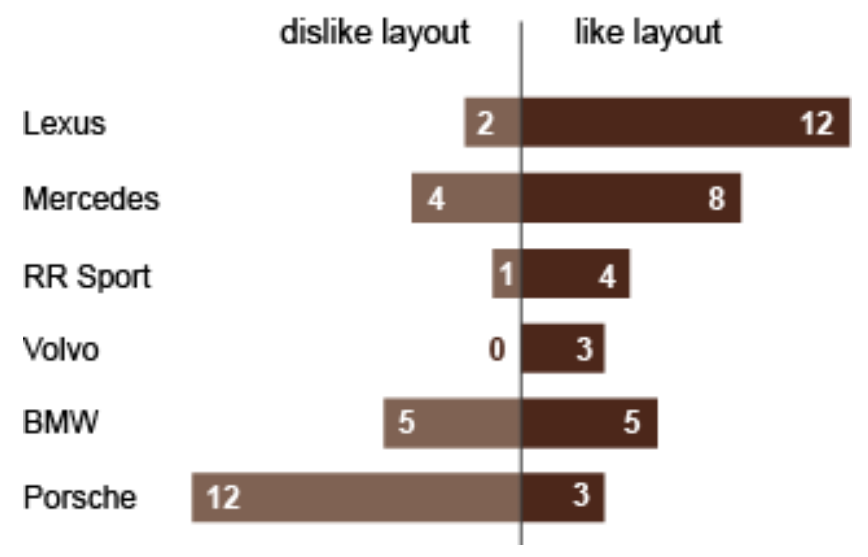

Figure 7: Distribution of comments relating to switch layout and spacing (combined in-car and on-bench data)

\section{Discussion}

In order to continuously improve products from the viewpoint of the customer, it is necessary not only to know where your product sits in relation to its competitors (hedonic testing and benchmarking), but also to understand the main underlying factors that influence affective responses such as preference, pleasure, or dissatisfaction. The research described in this paper specifically deals with customer perception of automotive switch-feel; however the holistic approach taken is intended to be applicable in a wider sensory science context.

\subsection{Switch-feel hedonics}

The research questions of whether luxury SUV customers can perceive differences in switch-feel, and whether as a group they show common hedonic judgements for switch-feel, have mainly been addressed through the acceptance and preference tests results.

From the acceptance scores in Tables 3 and 4 it has been shown that customers are able to discriminate between the feel of the switches to some extent, although a significant difference $(p<0.05)$ only exists between those switches with the highest and lowest median scores (Mercedes: 7 and BMW: 5). If the mean ranks are examined, a similar pattern is found, however small differences are revealed between those switches that have equal median scores. The rank order in decreasing level of acceptance is therefore Mercedes, Lexus, Volvo, Range Rover Sport, Porsche, and BMW.

The preference data (Fig 2) provides a different way of investigating customers' hedonic judgements by only focusing on the most and least preferred feeling switches. Different hedonic conclusions could be drawn depending on whether absolute frequency counts or the net difference between most and least preferred is considered. For instance, in the case of the Lexus' switches, when absolute counts are used, it is marginally more preferred than the Mercedes, but when the net difference is used the Mercedes appears considerable more preferable. The reason for this is that combining the most and least preferred data is masking the split in opinion that these switches provoke.

These cases of bimodality suggest that the sampling hypothesis of this study, whereby the SUV owners are considered to be a homogeneous group, does not hold. Although car manufacturers segment the overall market with different product offerings such as SUVs, executive saloons, or superminis; within SUV owners, hedonic judgements of switch-feel are not uniform. Bimodality in acceptance ratings is evident for the Lexus, Range Rover Sport, and BMW when assessed in context, and again for the Range Rover Sport when assessed on the bench. Similar results are seen in the preference data for the Lexus and Range Rover Sport. This leads the authors to hypothesise that the switches in these two vehicles embody some intrinsic or extrinsic characteristics which polarise hedonic opinion. These differences in switch-feel preferences have implications for product developers, because there is a danger that extra resources spent on developing improved switch-feel may not result in expected benefits to the customer. In future studies it is recommended that analysis methods such as preference mapping or cluster analysis are used to explore this issue in more detail. 
To understand better what switch characteristics influence perception of switch-feel, the semantic differential data has been analysed through a principle components analysis. It can be seen that significant differences between the Mercedes M-Class and BMW X5 ratings are mainly evident in adjective pairs with strong affective connotations such as cheap-expensive, or dull-interesting., and that more tangible adjective pairs such as clicky-smooth or flimsy-solid are not perceived as strongly different. This suggests that for these vehicles' switches, it is their affective characteristics rather than their operational characteristics that mainly differentiate one from another. The same patterns are not observed across all six samples though, highlighting the variability in participants' opinions, and the potential lack of homogeneity in the participant sample.

It is hypothesised that the reasons for the prominence of significant differences between the affective word pairs, as well as the variability in liking seen for some vehicles is related to how customers individually identify with these products. The SUV market sector in Europe has not been established as long as other sectors such as executive saloons, or family hatchbacks, and because of this, expectations of product characteristics are more varied. This can be seen in the way that SUVs are often marketed as 'lifestyle products' (Ford, 2005, BMW, 2006) which trade heavily on the social status associated with ownership (Boztepe, 2007). Participant demographics also show that customers for this class of vehicle are very diverse in terms of occupation and ownership reasons.

Inspecting the communalities of the variables within a three factor solution shows a medium to good fit ( 0.50 to 0.69 ) of nearly all apart from the 'old fashioned-modern' variable. The low to medium proportion of variance for this variable $(0.428)$ suggests that there may be a better solution. When a four factor solution is proposed however, communality of this variable improves to 0.865 , but the forth factor in the rotated solution appears to be a specific factor loading 'old fashioned-modern' only. Therefore, in spite of only $61 \%$ of the total variance being explained by the three factor solution, this has been chosen as the optimum solution.

As described in the results section, the extracted factors have been named based on the variables loading onto them. Whilst the proportion of variance explained by each factor suggests the degree of influence it is having, assumptions of importance can be reinforced by correlating the factor scores with the separate hedonic ratings. Table 6 lists these correlations as 0.505 for the 'affective' factor, 0.371 for 'robustness and precision', and 0.168 for 'silkiness'. These correlations are all significant at the 0.01 level; however this does not necessarily mean that the correlations are important. It is suggested that development resources are prioritised on affective characteristics such as how interesting, modern, and expensive the switches are, as well as making them less loose, flimsy and imprecise. The correlation of the affective factor with liking adds weight to the hypothesis that these factor variables play an important role in differentiating the switches. In addition, analysis of the qualitative data from the participants indicates that usability factors which were not included in the semantic differential test also have a bearing on customer satisfaction.

\subsection{Towards the development of specifications}

The most prominent usability characteristics identified in the content analysis are size, cheapness, and layout and spacing. Although is was specifically emphasised during the assessments that participants should focus on the feel of the switches, it is clear from the qualitative information given that they found it very difficult to disregard other perceived reasons for liking. Given the multimodal nature of product perception, and the complexity of the in-car environment this is perhaps not surprising.

Amongst the comments relating to switch size there were a number that explicitly related preference for a switch to the size of the participants finger. For example:

"Big square buttons [..] Bigger than width of my finger" - [male participant referring to Lexus switches]

This leads to the hypothesis that finger width should be taken into account when developing specifications for optimum switch sizes related to customer perception.

When the objective physical measurements of the switches are examined it does not appear that larger is always better. The Lexus has the largest switches at $20 \mathrm{~mm}$ wide $\mathrm{x} 20 \mathrm{~mm}$ tall, but it splits opinion 
between those participants who liked the large buttons, and those who thought they were too large. The implication here is that there is an upper limit to size, beyond which the effect is negative. The Volvo switches sized at $18 \times 15 \mathrm{~mm}$ are liked the most, and by comparing with relevant anthropometric data can be used to suggest guidelines for minimum and maximum switch sizes. Finger breadth at the distal joint varies from $13 \mathrm{~mm}$ for a $5^{\text {th }}$ percentile UK female, to $20 \mathrm{~mm}$ for a $95^{\text {th }}$ percentile UK male (DTI, 1998). Although $20 \mathrm{~mm}$ would be wider than the fingers of most of the population, we have seen that $20 \mathrm{~mm}$ is regarded by some customers as too large. With this in mind, the authors hypothesise that the optimum switch size for SUV centre consoles lies between $15 \times 15 \mathrm{~mm}$, and $18 \times 18 \mathrm{~mm}$, and will result in the least size related dissatisfaction. As this hypothesis is largely based on the qualitative data it would be necessary to validate through further study before adopting the sizes as a hard specification.

\subsection{The benefits of holistic research}

From this work, it is hoped that the benefits of using sensory science techniques within holistic consumer research, and applying it throughout the NPI process have been made evident.

When only the quantitative hedonic data are considered, it would be easy to conclude that liking of one switch-feel over another is mainly dependent on the operational characteristics of the switch mechanism. When the additional semantic differential data and qualitative findings are taken into account however, it can be seen that emotional and usability issues are perceived by the customers to be extremely important. In particular, the insights gained from the qualitative data have been used by the design departments in our collaborating OEMs to redesign aspects of vehicle user interfaces in the early stages of a new vehicle programmes. Conclusions from the quantitative empirical data have also been used to make development decisions within engineering departments in the later stages of the NPI process. Presenting our findings to both departments has meant a common understanding of the user's switch requirements now exists, and communication within the regular product development review meetings has improved.

Critically, the issue of turning customer insight into engineering specifications has also been initiated, and while this study has focussed on automotive HMI, it is intended that the learning will also be applicable within the wider product design and manufacturing industries.

\section{Acknowledgements}

This study is a part of the HMI for Intelligent Vehicles project within the University of Warwick Innovative Manufacturing Research Centre (IMRC). It is funded by a grant from the Engineering and Physical Science Research Council (EPSRC) with supplementary support from collaborating industrial partners. The authors would like to thank the above for their support.

\section{$9 \quad$ References}

Benson, R., MacRury, I., and Marsh, P., (2007). The secret life of cars and what they reveal about us. Not Actual Size Ltd., London

BMW (8/8/2006). The new BMW X5 [online]. Woodcliff Lake, NJ. BMW US. Available from www.bmwusfactory.com/media_center/releases/release.asp?intReleaseNum=209\&strYear=2006 [accessed 11 Sept 2007].

Boztepe, S. (2007). User value: competing theories and models. International Journal of Design, 1(2), $57-65$

Burns, A., and Evans, S. (2002). Empathic Design: A New Approach for Understanding \& Delighting Customers. International Journal of New Product Development and Innovation Management, 3(4)

Carbonaro, S., and Votava, C. (2005). Paths to a new Prosperity. The Nordic Textile Journal, The Textile Research Centre, University College of Borås, Sweden, pp71-85

Centre for Quality of Management. (2003). Kano's methods for understanding customer defined quality. Centre for Quality of Management Journal, 2(4) 1-36 
Cooper, R., Edgett, S., and Kleinschmidt, E. (2004). Benchmarking best NPD practices - III. Research Technology Management, 47(6), Nov-Dec 2004, 43-55

Cooper, R., and Kleinschmidt, E. (1991). New product processes at leading industrial firms. Industrial Marketing Management, 20, 137-147

Creusen, M., and Schoormans, J. (2005). The Different Roles of Product Appearance in Consumer Choice. J Prod. Innov. Manag. 22, 63-81

Daniel, W. (1990). Applied Nonparametric Statistics, $2^{\text {nd }}$ ed. Boston: PWS-Kent

Desmet, P., and Hekkert, P. (2007). Framework of product experience. International Journal of Design, 1(1) $57-66$

DTI (1998). Adultdata: The handbook of adult anthropometric and strength measurements - data for design safety. London. DTI. URN 02/798

Ely, B. (17/2/2006). Ten things that will change the way we live [online]. Forbes. Available from www.forbes.com/2006/02/16/sony-sun-cisco-cx_cd_0217feat_ls.html [accessed12 Sept 2007]

Ford (2005). Land Rover's Range Rover Sport makes its fashion debut on Madison Avenue [online]. Ford Motor Company. Available from: http://media.ford.com/article_display.cfm?article_id=21680 [accessed 11 Sept 2007]

Griffin, A. (1997). PDMA Research on new product development practices: updating trends and benchmarking best practices. J Prod. Innov. Manag. 14, 429-458

Griffin, A., and Hauser, J. (1993). The voice of the customer. Marketing Science. 12(1) 1-27

Hsu, S., Chuang, M., and Chang, C. (2000). A semantic differential study of designers' and users' product form perception. International Journal of Industrial Ergonomics, 25, 375-391

Immersion (2007). The value of haptics [online]. Immersion Corporation. Available from www.immersion.com/corporate/press_room/pdfs/Value-of-Haptics_May07v1-lr.pdf [accessed 12 Sept 2007]

Jindo, T., and Hirasago, K. (1997). Application studies to car interior of Kansei engineering. International Journal of Industrial Ergonomics, 19, 105-114

Jordan, P. (2000). Designing Pleasurable Products: An Introduction to the New Human Factors. 1st ed. London, Taylor \& Francis Ltd.

Kahn, K., Barczak, G., and Moss, R. (2006). Perspective: establishing an NPD best practices framework. J. Prod. Innov. Manag. 23, 106-116

Karlsson, S., Aronsson, N., and Svensson, K. (2003). Using semantic environment description as a tool to evaluate car interiors. Ergonomics, 46(13/14) 1408-1422

Khalid, H., and Helander, M. (2004). A framework for affective customer needs in product design. Theor. Issues in Ergon. Sci. 5(1), 27-42

Kinnear, P., and Gray, C. (2006). SPSS Made Simple, Hove: Psychology Press,

Krippendorff, K. (2004). Content Analysis: An Introduction to its Methodology. Thousand Oaks, CA: Sage 2004

Liu, Y. (2003). Engineering aesthetics and aesthetic ergonomics: Theoretical foundations and a dualprocess research methodology. Ergonomics, 46(13/14), 1273-1292

Lofthouse, V., Bhamra, T., and Burrow, T. (2005). A new way of understanding the customer for fibre manufacturers. International Journal of Clothing Science and Technology. 17(5) 349-360

Lyon, R. (2003). Product Sound Quality - from Perception to Design. Sound and Vibration, Mar 2003. $18-22$

Macdonald, A. (2001). Aesthetic intelligence: optimizing user-centred design. J. Eng. Design, 12(1), 3745 
Marsot, J. (2005). QFD: a methodological tool for integration of ergonomics at the design stage. Applied Ergonomics. 36, 185-192

Osgood, C.E., Suci, G., \& Tannenbaum, P. (1957). The Measurement of Meaning. Urbana, IL: University of Illinois Press

Rivière, P., Monrozier, R., Rogeaux, M., Pagès, J., and Saporta, G. (2006). Adaptive preference target: Contribution of Kano's model of satisfaction for an optimized preference analysis using a sequential consumer test. Food Quality and Preference, 17 572-581

Schütte, S., and Eklund, J. (2005). Design of rocker switches for work-vehicles - an application of Kansei Engineering. Applied Ergonomics, 36, 557-567

Schütte, S., Eklund, J., Axelsson, J., and Nagamachi, M. (2004). Concepts, methods and tools in Kansei Engineering. Theor. Issues in Ergon. Sci. 5(3), 214-231

Sheldon, M., Fillyaw, M., and Thompson, W., (1996). The use and interpretation of the Friedman test in the analysis of ordinal-scale data in repeated measures designs. Physiotherapy Research International. $1(4), 221-228$

Silverman, D. (2006). Interpreting Qualitative Data: Methods for Analyzing Talk, Text and Interaction, $3^{\text {rd }}$ ed. Thousand Oaks, London: SAGE Publications Ltd.

Smith, D. and Fletcher, J. (2004) .The Art and Science of Interpreting Market Research Evidence. Chichester: John Wiley and Sons Ltd.

Song, X., and Parry, M. (1997). A cross-national comparative study of new product development processes: Japan and the United States. Journal of Marketing, 61(2) Apr.1997, 1-18

Stevens, J. (2002). Applied Multivariate Statistics for the Social Science, $4^{\text {th }}$ ed. New Jersey: Lawrence Erlbaum Associates Inc.

van Kleef, E., van Trijp, H., and Luning, P. (2005). Consumer research in the early stages of new product development: a critical review of methods and techniques. Food Quality and Preference, 16, 181-201.

van Kleef, E., van Trijp, H., and Luning, P. (2006). Internal versus external preference analysis: An exploratory study on end-user evaluation. Food Quality and Preference, 17, 387-399.

Vehicle Certification Agency (2001). European Type Approval for Automotive Systems and Components (Revision 7), [online]. Bristol: VCA, VCA004. Available from: http://www.vca.gov.uk/downloads/index.asp?CategoryID=7 [Accessed 11 Dec 2007]

Veryzer, R., and Borja de Mozota, B. (2005). The impact of user-oriented design on new product development: An examination of fundamental relationships. J. Prod Innov. Manag. 22, 128-143

Warnock, A., Shumaker, A., and Delwiche, J., (2006). Consideration of Thurstonian scaling of ratings data, Food Quality and Preference, 17, 556-561

Wellings, T., Williams, M., and Tennant, C. (2005). Tactility, craftsmanship and the NPI process. SAE Transactions Journal of Passenger Cars: Mechanical systems. 2005-01-0977. 1104-1110 